\title{
The geographical distribution of dialysis services in Ghana
}

\author{
E. K. Tannor ${ }^{1}$, Y. A. Awuku², V. Boima ${ }^{3}$ and S. Antwi ${ }^{4}$
}

\begin{abstract}
Background: Chronic kidney disease (CKD) is an important global health challenge with increasing burden worldwide. CKD and acute kidney injury (AKI) may require renal replacement therapy (RRT) at some stages of the disease. Ghana currently has no renal transplant program. Dialysis services still remain a mirage to many chronic kidney disease patients in Ghana due to cost and paucity of hemodialysis machines. This survey highlights the geographical distribution of dialysis services in Ghana.

Methods: A cross-sectional situational survey of dialysis centers in the ten regions of Ghana was conducted by interviewing doctors and other health care professionals in all health institutions. Information on dialysis services, staff status, and number of hemodialysis machines and presence of peritoneal dialysis services in both private and government facilities was obtained and mapped out.

Results: Fifteen dialysis centers with a total of 103 hemodialysis machines were identified with majority 59 (57.2\%) in state-owned facilities. One half of regions in Ghana do not have any form of dialysis facilities. Majority 65 (63.1\%) of hemodialysis machines are in the Greater Accra region. Private hemodialysis services are available only in Greater Accra and Ashanti regions. There is no chronic peritoneal dialysis in Ghana but limited acute peritoneal dialysis. Ghana currently has eight nephrologists found only in the three government teaching hospitals. Most dialysis units across the country are supported by non-nephrologists.
\end{abstract}

Conclusion: There are few hemodialysis centers in Ghana; the distribution of which is skewed to few regions across the country. There is a need to improve dialysis services and equitable distribution across the country.

Keywords: Hemodialysis, Peritoneal dialysis, Geographical distribution, Ghana

\section{Background}

Chronic kidney disease (CKD) is an important global health problem with increasing incidence and prevalence. Currently, the worldwide prevalence is $10-13 \%$ [1-3] and similar estimates of $13.9 \%$ have been reported in Africa in a recent meta-analysis [4]. The prevalence in Ghana is however not known. Chronic kidney disease inevitably progresses to end-stage renal disease (ESRD) which requires renal replacement therapy (RRT) in the form of hemodialysis, peritoneal dialysis, or renal transplantation as the main modalities of treatment. It has been shown consistently that renal transplantation is cost effective and improves patient survival and quality

\footnotetext{
* Correspondence: ppawuku@gmail.com

${ }^{2}$ Department of Medicine and Therapeutics, School of Medical Sciences,

University of Cape Coast, Cape Coast, Ghana

Full list of author information is available at the end of the article
}

of life as compared to peritoneal dialysis and hemodialysis [5-11].

Unfortunately, Ghana has no national renal transplantation program but has had limited renal transplantation services in the capital city Accra. This started in the Korle-bu Teaching Hospital, a 1600-bed teaching hospital [12] in 2008. Seventeen patients have since had renal transplants since its inception [13], but none has been done recently. A few well-to-do patients currently travel abroad for kidney transplantation services. Hemodialysis therefore remains the main form of renal replacement therapy in the country for patients with ESRD. Unfortunately, hemodialysis services are not widely available in Ghana. It was shown by Antwi [13] in 2015 that hemodialysis was mainly found in three teaching hospitals and three private institutions in Ghana and was inadequate to serve Ghana's population in the light 
of the increased burden of kidney diseases. Acute kidney injury is also reported in hospital admissions and may require renal replacement therapy in severe cases. Mortality rates of acute kidney injury in adults in Africa ranges from $13.5-43.5 \%$ [14] and may increase in settings where dialysis services are unavailable.

Peritoneal dialysis in adults with end-stage renal disease is non-existent in Ghana though the modality has been used for the management of acute kidney injury in children in some parts of the country [13].

Due to increased cost of hemodialysis, most patients after diagnoses are left to their fate when they cannot afford hemodialysis. The National Health Insurance Scheme (NHIS) does not cover patients with end-stage renal disease requiring hemodialysis. The high cost of renal replacement therapy is a deterrent in the management of end-stage renal disease as patients have to pay out of pocket for hemodialysis sessions in Ghana.

The cost of frequent laboratory investigations and the treatment for hypertension, anemia, and calcium and phosphate abnormalities will further increase the cost of treatment of end-stage renal disease. The tragedy for those who even start hemodialysis is that they impoverish their families and then eventually die very depressed with poor quality of life [15].

Furthermore, due to inadequate hemodialysis centers and machines, patients diagnosed with infections such as human immunodeficiency virus (HIV) and viral hepatitis $\mathrm{B}$ and $\mathrm{C}$ in some facilities are prevented from accessing the few hemodialysis machines available. This results in even fewer patients getting access to hemodialysis. Currently, the population of Ghana is about 27 million [16] and with the high prevalence rate of the causes of chronic kidney disease, there might be the need to increase the number and distribution of dialysis offered. The current number and geographical distribution of hemodialysis and peritoneal dialysis units remain unknown.

We set out to establish the number of hemodialysis machine in the various government and private facilities and to map out the regional distribution of renal replacement therapy in Ghana.

\section{Methods}

It was a cross-sectional situational survey of dialysis centers in all the ten regions of Ghana as at 31 December 2016. Information was sought by interviewing doctors and health care workers providing renal care in all health care facilities in all the regions in Ghana to ascertain the availability of dialysis services in both government and private facilities. The presence of peritoneal dialysis services, the availability of trained staff, specialist, and nephrologists were also documented. The number of patients on dialysis in the centers was also documented. The distribution of facilities with hemodialysis centers across the country were mapped using Google Earth. For facilities not already mapped on Google maps, Google search was used to retrieve the physical address of the facility and this was used in estimating the location of the facility.

\section{Ghana's administrative regions and population}

Ghana is a country located in West Africa bounded by Burkina Faso on the north, Togo on the eastern border, Côte d'ivoire on the west, and the gulf of Guinea on the south. Ghana has a gross domestic product (GDP) of 37.54 billion US dollars and a GDP per capita of 1696.64 US dollars as at 2016 [17].

Ghana has a geographical surface area of $238,540 \mathrm{~km}$ and ten administrative regions. Greater Accra is the smallest region measuring $3245 \mathrm{~km}^{2}$ and hosts the national capital Accra with a population of 4,010,054 [18]. The Northern region with its capital Tamale is the largest region in Ghana measuring $70,384 \mathrm{~km}^{2}$ with a population of 2,479,461 followed by Brong Ahafo with a surface area of $39,557 \mathrm{~km}^{2}$ in the middle belt of Ghana with a population of $2,310,983$. Ashanti region also in the middle belt with capital Kumasi has a population of $4,780,380$ and a surface area of $24,389 \mathrm{~km}^{2}$ [18]. The other regions are the Western region, Central region, Brong Ahafo region, Upper East region, Upper West region, and the Volta region as shown in Fig. 1.

\section{Results}

As at December 2016, there were 15 centers offering in-center hemodialysis services in Ghana. This included 7 in the government-owned facilities and 8 in private-owned centers. There were 103 functioning hemodialysis machines in Ghana with 59 (57.3\%) in the government-owned hospitals and 44 (42.7\%) in private-owned health centers. The government-owned hospitals with hemodialysis machines were mainly the teaching hospitals in the Northern, Ashanti, Central, the Greater Accra, and the Volta regions.

This included 18 functioning machines in the Renal Unit of Korle-bu Teaching Hospital besides 10 machines in the National Cardiothoracic Unit within the Korle-bu Teaching Hospital. The cardiothoracic unit is a 32-bed facility established in the 1960s but was recommissioned in 1992 for the management of thoracic and cardiac cases surgically. It is one of the few functioning cardiothoracic centers in Africa. The National Cardiothoracic Centre receives referrals from other African countries such as Benin, Togo, Nigeria, Ivory Coast, Cameroon, Ethiopia, and Tanzania.

There are 8 functioning machines in the Police Hospital in Accra, 10 in the Cape Coast Teaching Hospital, 8 in the Komfo Anokye Teaching Hospital, 3 


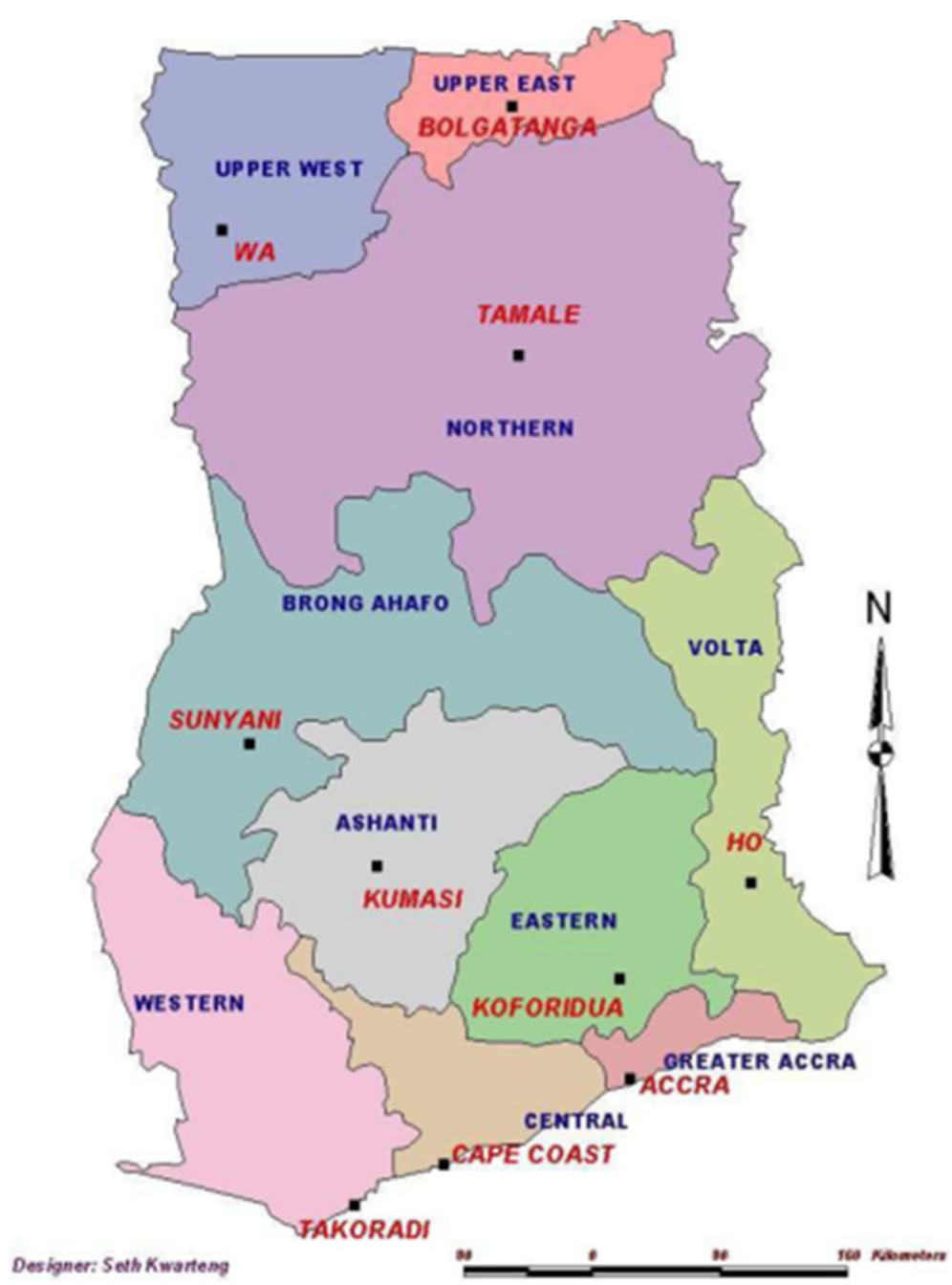

Fig. 1 The administrative regions of Ghana with regional capitals [18]. The regions and administrative capitals in Ghana [19, 20]

in the Tamale Teaching Hospital, and 2 in the Ho Regional Hospital in the Volta region as shown in Table 1. The Korle-bu Teaching Hospital has the greatest number of patients on dialysis in Ghana: 250 patients on hemodialysis as at December 2016. This was followed by the Cape Coast Teaching Hospital (68 patients) and the National cardiothoracic unit (65 patients). Komfo Anokye Teaching Hospital had the least number of patients on hemodialysis as shown in Table 1.

Chronic peritoneal dialysis was not available in any of the teaching hospital for the management of endstage renal disease. Acute peritoneal dialysis was present in a large scale in Komfo Anokye Teaching Hospital for the management of acute kidney injury in pediatric population only. Acute peritoneal dialysis has recently been introduced in the Tamale Teaching Hospital, the Korle-bu Teaching Hospital and the Cape Coast Teaching Hospital on a small scale.
Some of the hemodialysis centers even in some teaching hospitals were not manned by trained nephrologists. The Cape Coast Teaching Hospital is manned by a consultant physician and two medical officers (specialist-intraining) and the Ho Regional Hospital is manned by a medical officer as shown in Table 1.

\section{Private-owned dialysis centers in Ghana}

Private-owned hemodialysis facilities were identified in only two out of the ten regions in Ghana. These facilities were found only in Accra and Kumasi, which are the regional capitals of the Greater Accra and Ashanti regions respectively. Six private facilities were identified in Accra and two in Kumasi in the Ashanti region within the study period. The private facilities in Accra include the Accra kidney clinic, the Trust Hospital, the Meridian Hospital, the Ghana Canada Hospital, Bengali Hospital, and the Labone dialysis clinic. It was found that most of the private-owned facilities were run by medical officers, 
Table 1 Dialysis services within government-owned hospitals in Ghana

\begin{tabular}{|c|c|c|c|c|}
\hline Government hospital & $\begin{array}{l}\text { Number of functioning } \\
\text { hemodialysis machines }\end{array}$ & $\begin{array}{l}\text { Personnel in-charge } \\
\text { of unit }\end{array}$ & Number of patients & $\begin{array}{l}\text { Peritoneal dialysis } \\
\text { availability }\end{array}$ \\
\hline $\begin{array}{l}\text { Korle-bu Teaching } \\
\text { Hospital }\end{array}$ & 18 & $\begin{array}{l}4 \text { nephrologists } \\
4 \text { nephrology trainees }\end{array}$ & 250 & No \\
\hline Cardiothoracic unit & 10 & 1 nephrology trainee & 65 & No \\
\hline $\begin{array}{l}\text { Komfo Anokye } \\
\text { Teaching Hospital }\end{array}$ & 8 & $\begin{array}{l}3 \text { nephrologists } \\
2 \text { specialist physicians }\end{array}$ & 22 & Yes for acute dialysis in children only \\
\hline $\begin{array}{l}\text { Tamale Teaching } \\
\text { Hospital }\end{array}$ & 3 & $\begin{array}{l}1 \text { nephrologist (Cuban) } \\
1 \text { specialist physician }\end{array}$ & 45 & Yes for acute dialysis in children only \\
\hline $\begin{array}{l}\text { Cape Coast Teaching } \\
\text { Hospital }\end{array}$ & 10 & $\begin{array}{l}1 \text { consultant physician } \\
2 \text { medical officers }\end{array}$ & 68 & $\begin{array}{l}\text { Yes for acute dialysis both adult } \\
\text { and children }\end{array}$ \\
\hline Ho Teaching Hospital & 2 & 1 medical officer & 26 & No \\
\hline Police Hospital, Accra & 8 & 1 medical officer & 25 & No \\
\hline
\end{tabular}

dialysis nurses, and some nephrologists only on parttime basis. The number of functioning hemodialysis machines identified in these facilities is shown in Table 2.

Among private-owned facilities, Bengali clinic had the highest number of patients on hemodialysis of 34 , followed by Ghana Canada clinic with 24 patients. Peace and Love Hospital had the least number of patients of 10 on hemodialysis as at December 2016 as shown in Table 2.There were no peritoneal dialysis services in any of these private facilities for either acute kidney injury or chronic kidney disease.

\section{Regional distribution of dialysis units in Ghana}

As shown in Table 2, the distribution of governmentand private-owned dialysis centers is skewed towards the
Greater Accra, Ashanti, and Central regions. The Upper East, Upper West, Brong Ahafo, Eastern, and Western region do not have any form of renal replacement therapy for the management of renal diseases (Fig. 2).

Private-owned hemodialysis centers are only in the greater Accra and Ashanti regions. These are in the regional capitals alone, i.e., Accra and Kumasi. There were none in the eight other regions and as shown in Table 3.

The overall national hemodialysis machines in both private- and government-owned facilities per million population (pmp) are 4.20. The greater Accra region has the highest number of dialysis machines of 65 (63.1\%) in both the private- and government-owned hospitals. The Greater Accra region has 16.2 hemodialysis machines pmp in both private- and government-owned facilities followed by the

Table 2 The regional distribution of dialysis services within private-owned facilities in Ghana

\begin{tabular}{|c|c|c|c|c|c|}
\hline Region & Private facilities & Name of facility & Number of hemodialysis machines & Number of patients & Personnel in-charge of unit \\
\hline Eastern & No & NA & NA & - & NA \\
\hline Volta & No & NA & NA & - & NA \\
\hline \multirow[t]{6}{*}{ Greater Accra } & Yes & Accra kidney clinic & 7 & 23 & $\begin{array}{l}1 \text { nephrologist } \\
1 \text { medical officer }\end{array}$ \\
\hline & Yes & Trust Hospital & 4 & 20 & 1 medical officer \\
\hline & Yes & Bengali clinic & 5 & 34 & $\begin{array}{l}1 \text { nephrologist (locum) } \\
1 \text { medical officer }\end{array}$ \\
\hline & Yes & Meridian clinic & 5 & 12 & 1 renal nurse \\
\hline & Yes & Ghana Canada Clinic & 5 & 24 & 1 nephrologist (locum) \\
\hline & Yes & Ababio clinic (Labone) & 3 & 12 & 1 renal nurse \\
\hline Central & No & NA & NA & - & NA \\
\hline Western & No & NA & NA & - & NA \\
\hline Brong Ahafo & No & NA & NA & - & NA \\
\hline \multirow[t]{2}{*}{ Ashanti } & Yes & Peace and Love Hospital & 5 & 10 & 1 senior medical officer \\
\hline & Yes & Naghe Clinic & 10 & 16 & 1 principal medical officer \\
\hline Upper East & No & NA & NA & - & NA \\
\hline Upper West & No & NA & NA & - & NA \\
\hline Northern & No & NA & NA & - & NA \\
\hline
\end{tabular}




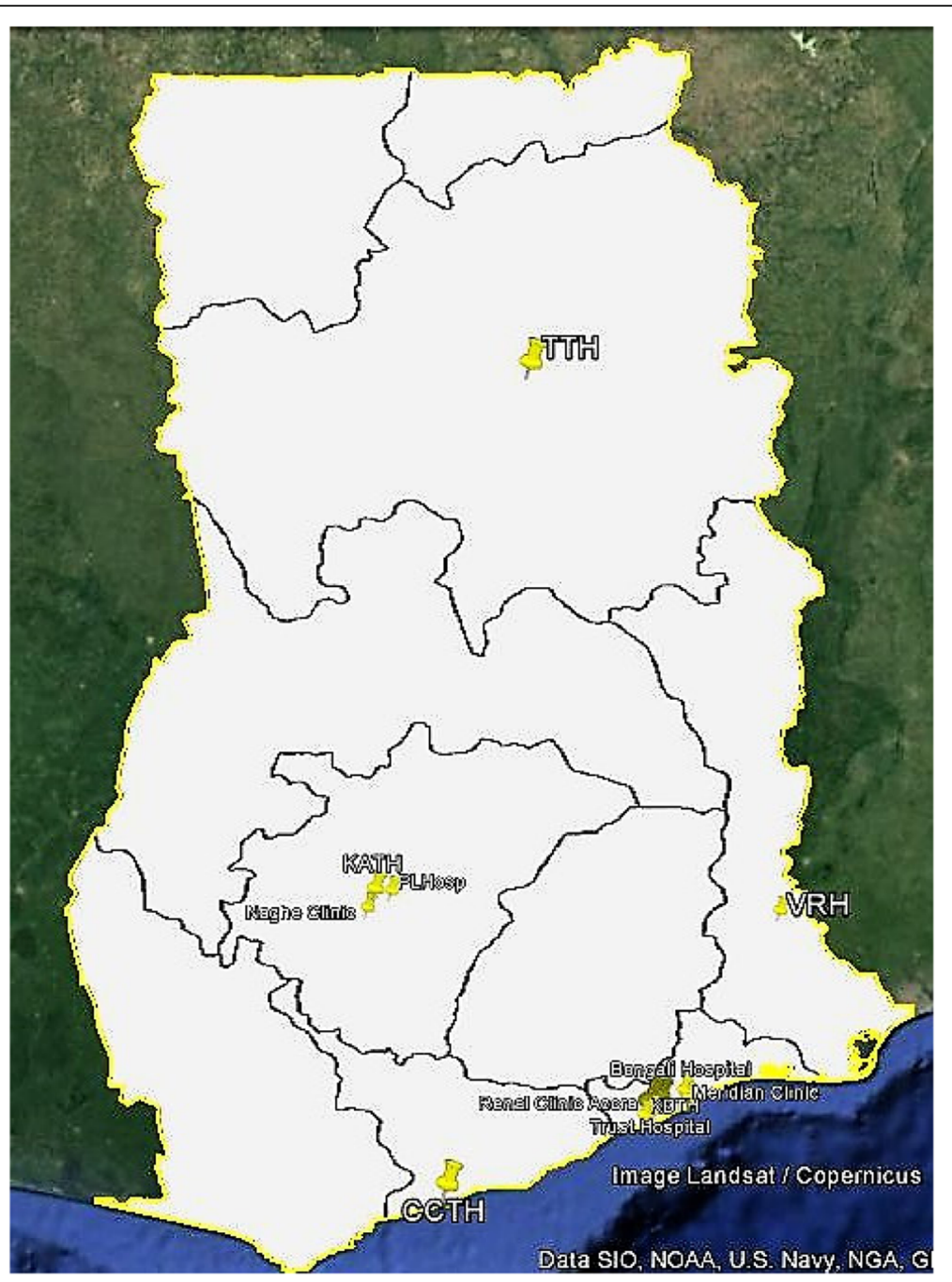

Fig. 2 The geographical distribution of the dialysis units in Ghana

Table 3 The regional distribution of hemodialysis machines per million population (pmp) in Ghana

\begin{tabular}{|c|c|c|c|c|c|c|}
\hline Region & Public units $(n)$ & Private units $(n)$ & Total $(n)$ & Total (\%) & Population per region & Hemodialysis machines (pmp) \\
\hline Eastern & 0 & 0 & 0 & 0 & $2,633,154$ & 0 \\
\hline Volta & 2 & 0 & 2 & 1.9 & $2,118,525$ & 0.94 \\
\hline Greater Accra & 36 & 29 & 65 & 63.1 & $4,010,054$ & 16.20 \\
\hline Central & 10 & 0 & 10 & 9.7 & $2,201,863$ & 4.54 \\
\hline Western & 0 & 0 & 0 & 0 & $2,376,021$ & 0 \\
\hline Brong Ahafo & 0 & 0 & 0 & 0 & $2,310,938$ & 0 \\
\hline Ashanti & 8 & 15 & 23 & 22.3 & $4,780,380$ & 4.81 \\
\hline Upper east & 0 & 0 & 0 & 0 & $1,046,545$ & 0 \\
\hline Upper West & 0 & 0 & 0 & 0 & 702,110 & 0 \\
\hline Northern & 3 & 0 & 3 & 2.9 & $2,479,461$ & 1.21 \\
\hline Total & 59 & 44 & 103 & & $24,658,823$ & 4.20 \\
\hline
\end{tabular}


Ashanti region of 4.81 hemodialysis machines pmp and Central region of 4.54 as shown in Table 3.

\section{Peritoneal dialysis in Ghana}

Peritoneal dialysis as a modality for managing chronic dialysis is not practiced in Ghana currently. It is however available for the management of acute kidney injury in the Komfo Anokye Teaching Hospital, to a very less extent in the Korle-bu Teaching Hospital, Cape Coast Teaching Hospital, and Tamale Teaching Hospital.

\section{Discussion}

This study is an audit of hemodialysis services in Ghana showing the regional distribution of hemodialysis facilities and number of hemodialysis machines in Ghana. There have been some improvements in the dialysis facilities in Ghana since the study by Antwi in 2014 [13]. There are now more private hemodialysis facilities but not much improvement in numbers in the state-owned facilities. The use of peritoneal dialysis as a form of renal replacement therapy in the management of acute and chronic kidney diseases in Ghana is however still minimal. The unavailability of chronic peritoneal dialysis in many sub-Saharan Africa including Ghana has been attributed to the high cost of the peritoneal dialysis fluid making it comparable or even more expensive than in-center hemodialysis sessions [21]. In developed countries, the cost of providing peritoneal dialysis is less than the cost of hemodialysis due to economies of scale in the production of dialysate but this is not so in developing countries [22] such as Ghana. Measures to produce peritoneal dialysate locally and lowering of import duties on peritoneal dialysate and peritoneal dialysis catheters have been suggested as important in decreasing the cost of peritoneal dialysis. Training of surgeons and physicians on Tenckhoff catheter insertion may provide peritoneal dialysis valuable modality as a renal replacement therapy with comparable quality of life to hemodialysis [11].

Acute peritoneal dialysis is however practiced in many regional and district hospitals in Ghana using improvised techniques and self-constituted fluids to decrease cost [23]. This has proven very useful in children for the management of acute kidney injury in some teaching hospitals in the country. The cost of peritoneal fluid is still a challenge for chronic peritoneal dialysis.

All the hemodialysis facilities are concentrated in the capital cities of the Greater Accra region, Ashanti region, the Central region, and Volta region with most regions bereft of any form of renal replacement therapy for the management of acute and chronic kidney diseases.

The unavailability of kidney transplantation services in Ghana leaves a lot of end-stage renal disease patients on hemodialysis for longer duration. Most patients do not get kidney transplant though it has been shown to be the best modality for renal replacement therapy as compared to hemodialysis and peritoneal dialysis [5-10]. In Ghana, patients on hemodialysis have high mortality rate [24]. Our study reveals that hemodialysis machines per million population in Ghana is 4.20 much lower than other African countries such as Egypt, South Africa, and Nigeria [25]. The dialysis rates across Africa are less than 20 per million population as compared to a global prevalence of $223 \mathrm{pmp}$ [26]. Ghana falls far below the 20 hemodialysis machines per million population. Most regions in Ghana do not have any form of renal replacement therapy and are therefore transferred to the few centers for management with varied outcomes.

There is the need to improve the number of dialysis machines per million population considering the perceived high prevalence of chronic kidney disease and acute kidney injury in Africa and Ghana as we work to establish a renal transplant services.

The regulation of the hemodialysis services to provide adequate dialysis, without the spread of infection with ultrapure water quality with the reverse osmosis (RO) system is imperative [27]. Unfortunately, dialysis service in Ghana is not officially regulated and regular checks for water quality are done at the discretion of the service providers. This needs to be addressed to provide quality dialysis services in all centers across the country to avoid cross infections among patients with end-stage renal disease and acute kidney injury.

Most hemodialysis facilities especially in the privateowned facilities are not managed by trained nephrologists or physicians but by medical officers and renal nurses. This is because Ghana has very few nephrologists of less than one per million population just as other African countries in sub-Saharan Africa [25]. These nephrologists are found only in the teaching hospitals in Accra and Kumasi. It was reported in an earlier study that Ghana had 0.1 nephrologists per million population as compared to $0.6 \mathrm{pmp}$ in Nigeria, $0.5 \mathrm{pmp}$ in Kenya, $4.5 \mathrm{pmp}$ in Morocco, and $6.5 \mathrm{pmp}$ in Egypt [21]. The total number of nephrologist have subsequently improved from $0.1 \mathrm{pmp}$ in 2010 to 0.26 pmp currently, but this is still inadequate for the population in Ghana. We do acknowledge the limitation of our study as data was obtained by interviewing staff or health care workers in each region. This is because there is no designated outfit responsible for registering dialysis facilities in Ghana.

The authors believe that kidney transplantation program should be established in the country. The country needs to educate the populace about prevention of kidney disease and sensitize the public about kidney donation. Chronic peritoneal dialysis should be introduced for the management of end-stage renal disease. Hemodialysis centers and machines per population should be increased 
in both private-owned and government-owned facilities. Since cost of dialysis is also an important limiting factor affecting accessibility of renal replacement, there is the need for governmental support for renal replacement therapy. There is the need for the various dialysis facilities in Ghana to be regulated to provide quality renal services to patients with renal diseases.

\section{Conclusion}

The distribution of renal dialysis services is skewed to a few cities and regions. There is an urgent need to establish more dialysis services equitably across the country to meet the need of the growing prevalence of chronic kidney disease and for the management of acute kidney injury in all the ten regions of Ghana.

\section{Acknowledgements}

We appreciate the effort and contribution of the doctors and other health workers across dialysis facilities in Ghana who contributed data towards this manuscript. We also acknowledge Mr. EvansXorseAmuzu for helping with the mapping out of the locations of all the facilities.

\section{Funding}

This study is self-funded by the authors.

\section{Availability of data and materials}

The datasets during and/or analyzed during the current study is available from the corresponding author on a reasonable request.

\section{Authors' contributions}

All authors contributed equally to the study concept and design, acquisition of data, interpretation of data, and critical revision of the manuscript. All authors read and approved the final manuscript.

\section{Ethics approval and consent to participate}

A waiver was obtained from the Cape Coast Teaching Hospital ethical review committee.

\section{Consent for publication}

Not applicable.

\section{Competing interests}

The authors declare that they have no competing interests.

\section{Publisher's Note}

Springer Nature remains neutral with regard to jurisdictional claims in published maps and institutional affiliations.

\section{Author details}

'Department of Medicine and Renal Unit, Komfo Anokye Teaching Hospital, Kumasi, Ghana. ${ }^{2}$ Department of Medicine and Therapeutics, School of Medical Sciences, University of Cape Coast, Cape Coast, Ghana. ${ }^{3}$ Department of Medicine and Renal Unit, Korle-bu Teaching Hospital, Accra, Ghana. ${ }^{4}$ Paediatric Nephrology Unit, Department of Child Health, Kwame Nkrumah University of Science and Technology/Komfo Anokye Teaching Hospital, Kumasi, Ghana.

Received: 21 August 2017 Accepted: 4 January 2018

Published online: 17 January 2018

\section{References}

1. Stenvinkel P. Chronic kidney disease: a public health priority and harbinger of premature cardiovascular disease. J Intern Med. 2010;268:456-67.

2. Coresh J, Selvin E, Stevens LA, Manzi J, Kusek JW, Eggers P, et al. Prevalence of chronic kidney disease in the United States. J Am Med Assoc. 2007; 298(17):2038-47.
3. Eknoyan $\mathrm{G}$, Lameire N, Barsoum R, Eckardt KU, Levin A, Levin N, et al. The burden of kidney disease: improving global outcomes. Kidney Int. 2004;66(4):1310-4.

4. Stanifer JW, Jing B, Tolan S, Helmke N, Mukerjee R, Naicker S, et al. The epidemiology of chronic kidney disease in sub-Saharan Africa: a systematic review and meta-analysis. Lancet Glob Health. 2014;2(3):e174-81.

5. Valderrabano F, Jofre R, Lopez-Gomez JM. Quality of life in end-stage renal disease patients. Am J Kidney Dis. 2001;38(3):443-64.

6. Alvares J, Cesar CC, AcurcioFde A, Andrade El, Cherchiglia ML. Quality of life of patients in renal replacement therapy in Brazil: comparison of treatment modalities. Qual Life Res. 2012;21(6):983-91.

7. Kovacs AZ, Molnar MZ, Szeifert L, Ambrus C, Molnar-Varga M, Szentkiralyi A, et al. Sleep disorders, depressive symptoms and health-related quality of life- - a crosssectional comparison between kidney transplant recipients and waitlisted patients on maintenance dialysis. Nephrol Dial Transplant. 2011;26(3):1058-65.

8. Purnell TS, Auguste P, Crews DC, Lamprea-Montealegre J, Olufade T, Greer $R$, et al. Comparison of life participation activities among adults treated by hemodialysis, peritoneal dialysis, and kidney transplantation: a systematic review. Am J Kidney Dis. 2013;62(5):953-73.

9. Czyzewski L, Sanko-Resmer J, Wyzgal J, Kurowski A. Assessment of healthrelated quality of life of patients after kidney transplantation in comparison with hemodialysis and peritoneal dialysis. Ann Transplant. 2014;19:576-85.

10. Liem YS, Bosch JL, Arends LR, Heijenbrok-Kal MH, Hunink MG. Quality of life assessed with the Medical Outcomes Study Short Form 36-Item Health Survey of patients on renal replacement therapy: a systematic review and meta-analysis. Value Health. 2007;10(5):390-7.

11. Tannor EK, et al. Quality of life in patients on chronic dialysis in South Africa: a comparative mixed methods study. BMC Nephrol. 2017;18(1):4.

12. Govindaraj R, Obuobi A, Enyimayew N, Antwi P, Ofosu-Amaah S. Hospital autonomy in Ghana: the experience of Korle Bu and Komfo Anokye Teaching hospitals. Boston: Data for Decision Making Project, Harvard School of Public Health; 1996.

13. Antwi S. State of renal replacement therapy services in Ghana. Blood Purif. 2015:39(1-3):137-40

14. Adu D, Okyere P, Boima V, Matekole M, Osafo C. Community-acquired acute kidney injury in adults in Africa. Clin Nephrol. 2016:86(13):48.

15. Boima V, Ganu V, Adjei D et al. Psychological wellbeing and quality of life among chronic kidney disease patients in Ghana. Changing Trends Mental Health Care Res Ghana. 2015(3).

16. http://www.statsghana.gov.gh/pop_stats.html. Accessed 20 Feb 2017.

17. http://www.tradingeconomics.com/ghana/gdp. Accessed 2 Apr 2017.

18. Service GS. 2010 population and housing census: demographic, social, economic and housing characteristic report 2013.

19. https://en.wikipedia.org/wiki/List_of_Ghanaian_regions_by_area. Accessed 23 Dec 2016.

20. http://www.pub.iaea.org/MTCD/Publications/PDF/CNPP2012_CD/ countryprofiles/Ghana/Ghana.htm2012. Accessed 2 Apr 2017.

21. Katz IJ, Gerntholtz T, Naicker S. Africa and nephrology: the forgotten continent. Nephron Clin Pract. 2010:117(4):320-7.

22. Karopadi AN, Mason G, Rettore E, Ronco C. Cost of peritoneal dialysis and haemodialysis across the world. Nephrol Dial Transplant. 2013:2553-69.

23. Antwi S. Peritoneal dialysis using improvised PD catheter and selfconstituted dialysis solution. 2010.

24. Eghan BA, Amoako-Atta K, Kankam CA, Nsiah-Asare A. Survival pattern of hemodialysis patients in Kumasi, Ghana: a summary of forty patients initiated on hemodialysis at a new hemodialysis unit. Hemodial Int. 2009;13(4):467-71.

25. Naicker S, Eastwood JB, Plange-Rhule J, Tutt RC. Shortage of healthcare workers in sub-Saharan Africa: a nephrological perspective. Clin Nephrol. 2010;74:S129-33.

26. El Matri A. ESRD management in Africa during the last decade. Clin Nephrol. 2015;83(7 Suppl 1):11-3.

27. Laurence RA, Lapierre ST. Quality of hemodialysis water: a 7-year multicenter study. Am J Kidney Dis. 1995;25(5):738-50. 